\title{
Perceived Stress and its Social-Individual Predicors among Infertile Couples Referring to Infertility Center of Alzahra Hospital in Tabriz in 2013
}

\author{
Fahimeh Sehhatie Shafaie ${ }^{1}$, Mojgan Mirghafourvand ${ }^{2}$, Marieh Rahimi ${ }^{*}$
}

\begin{abstract}
Objectives: Infertility is threatening and stressful as a big crisis in life psychologically. Since there still are many ambiguities about the infertility's being stressful. This study is done for defining the perceived stress among infertile couples and its social-individual predictors.

Materials and Methods: This study is a sectional one which was done on 322 infertile couples referring to the infertility center at Alzahra Hospital in Tabriz. Sampling method was available. The gathering data instruments included social-individual particulars questionnaire and perceived stress scale (PSS) questionnaire which was completed as self-completion by the participants. The multivariate linear regression analysis method was used for defining the social-individual predictors of perceived stress.

Results: The findings of the research showed that mean (standard deviation) of perceived stress among women was 27.4 (6.0) and 25.9 (5.3) among men out of 0-56 grade range and there was statistically significant difference between men and women due to perceived stress $(\mathrm{P}<0.001)$. The variable of monthly income sufficiency for living expenses, occupation, type of current treatment, Method of treatment, Etiology of infertility, methods of contraception were the predictors of perceived stress.

Conclusion: The results of this research showed higher perceived stress among women compared to men; therefore it is necessary to provide approaches for reducing the perceived stress focusing on its predictive variables for recovering the couples' mental status. Keywords: Perceived stress, Infertile couples, Social-individual predicators, PSS
\end{abstract}

\section{Introduction}

Stress in a concept is assumed as an event which is resulted from external upsetting conditions and it also points to the person's reaction to the disorder and finally its compounding concepts means understanding an event and its appraisal of the adequacy of confronting with stressful source (1).

Infertility accompanies with physical, mental, emotional problems and social stress (2) which clinically is defined as inability for pregnancy after 12 months unprotected sexual intercourse (3), which can influence on all the life aspects (4). As a multidimensional problem (5), infertility is considered as an important threat for health in all over the world (6) that its incidence is about $24.9 \%$ in Iran (7) and $8-10 \%$ throughout the world (8). Child birth is considered as the most important aspect in most of the marriages and delivery is considered as the expected phenomena of couples' sex (9). When a couple are unable to fertility, it will cause devastating consequences such as mental stress (10), which is one of the health problems (11).

Expensive and tedious medical procedures for treating infertility and doubt and disappointment undermine the basis of infertile couples' life (12). Infertility disorders the interrelations as one of the stressing factors (13). Infertility stress is a set of symptoms which occurs following infertility in the person which is connected with emotions and thoughts related to infertility and struggle for being released of these thoughts and emotions (14). Infertility's stress occurs persistent and the relationship between stress and infertility becomes as a vicious cycle (15).

Having compared the infertile couples with fertile couples, Andrews et al. concluded that stress has negative effect on marital function and life quality regardless of its source (infertility stress or stress resulted from any other source) (16). In another study, Peterson et al. stated that the couples who experienced infertility stress expresses higher level of compatibility and marital consent compared to those who have another stress but at the same level (17). Meanwhile, it was shown that considerable increasing in stress can lead to considerable decrease in compatibility and marital consent and highest level of marital stress is among the couples who could not be fertile (18).

Despite increasing the attention to stress in infertility, perceived stress was being studied less by the researchers (19) and it is highly questionable that how much the stressful events of life can have direct effect on physical and psychological health (20).

According to Nohi et al, adaptation to stress influenced

Received 7 March 2014, Revised 21 May 2014, Accepted 19 June 2014, Available online 20 July 2014

${ }^{1}$ Instructor, Department of Midwifery, Tabriz University of Medical Sciences, Tabriz, Iran. ${ }^{2}$ Assistant Professor, Department of Midwifery, Tabriz University of Medical Sciences, Tabriz, Iran. ${ }^{3}$ Graduate Student, Department of Midwifery, Tabriz University of Medical Sciences, Research Committee, Tabriz, Iran.

*Corresponding Author: Marieh Rahimi, Tel: 09122369204, Email: marieh.rahimi@yahoo.com 
on physical, mental factors and social function. Therefore, if a person can succeed in confronting with stress and daily tensions, he will help in promoting his physical, mental health and improving his social function (21), since perceived stress is introduced as an important and effective issue in fertility health among infertile couples and considering the important of mental health of infertile couples in promoting their health and the role of stress in infertility treatment results, this study was done for defining the perceived stress and its social-individual predictors among infertile couples.

\section{Materials and Methods}

Design and sampling

This study is a sectional one which was done on 322 infertile couples (322 women and 322 men) referring to infertility center of Alzahra Hospital in Tabriz. Sampling method was available. Couples with eligibility criteria entered the study and necessary explanation was given about the study and written consent was taken from them, ultimately questionnaires were completed as selfcompletion method.

According to the primary study on 30 couples and considering $\mathrm{SD}=10.7, \mathrm{M}=33.8, \mathrm{D}=0.05, \alpha=0.05$ and $\mathrm{B}=0.2$, the sample volume was computed for 313 and finally 322 couples were studied.

Eligibility criteria for entering to the study includes tendency for participating in research, Iranian nationality, primary infertility, being treated for infertility, being literate, not occurring stressful action in last 6 months, not suffering from mental disorders or any other treatment in this area according to the couples' declaration.

\section{Gathering Data}

The used data in this study includes: Individual- social particulars questionnaires including questions about gender, age, academic status, occupation status, marriage duration, infertility duration, duration of infertility treatment, etiology of infertility, method of treatment, record of using contraceptives, reason of action for treatment, record of failure in treatment, efficiency of monthly income for life expenses, family members who live with the couple, number of congestion, and BMI (Body Mass Index). Perceived stress scale (PSS) questionnaire which was prepared in 1983 by Kohen et al, has 3 copies of 4, 10 and 14 items was used for measuring the perceived general stress in last month. This tool measures the thoughts and emotions about stressful action, control, confronting and overcoming mental pressure and experienced stresses. Meanwhile, the risk factors were studied in behavioral disorders and showed the stressful relation. Perceived stress scale having 14 questions was used in this study. Each question has 5 choices, the half of which was grades directly $(0,1,2,3,4)$ and the other half as inverse $(4,3,2,1,0)$. All the items were grades as Likert scale $(0=$ never, $1=$ low, $2=$ average, $3=$ high, $4=$ very high). The grades range from 0 to 56 . It shall be noted that grading 7 items of the questions in this questionnaire
$(4,5,6,7,9,10,13)$ which has positive concept, is as reverse ( $0=$ very high, $1=$ high, $2=$ average, $3=$ low, $4=$ never $)$ and reliability was defined in this study by test-posttest on 30 couples from two dimensions of repeatability (ICC) and internal consistency (Cronbach Alpha coefficient). ICC (95\% confidence interval) and Cronbach Alpha was respectively $0.76(0.55-0.87)$ and 0.78 .

\section{Data Analysis}

For describing personal-individual particulars and perceived stress, the descriptive statistics including frequency and percent, mean and standard deviation were used. For defining the predictors of perceived stress, at first the relationship between perceived stress and personal-social particulars was measured by t-test and one way ANOVA and then for predicting the effects of any of the independent variables (personal and social particulars) on dependent variable (perceived stress) and defining its variance, those independent variables who $\mathrm{P}$-value in two-variable test was less than 0.2 were entered into multivariate linear regression as Backward strategy. SPSS 15 was used for data analysis.

\section{Results}

Almost half of the couples (53.0\%) were treated for infertility for less than 3 year. Most of the couples (68.5\%) had contraceptive methods. More than one third of the couples (38.5\%) reported the most received treatment type as Intra-uterine insemination (IUI). More than one third of the couples mentioned the most etiology of infertility in women (32.9\%). About half of the couples (47.7\%) mentioned the duration of marriage for more than 5 years and infertility duration was more than 5 years in $40.4 \%$ of the couples (Table 1).

About half of the women participating in the study $(47.2 \%)$ and about $60.6 \%$ of men was in a group ranges from 30-40 years old whose mean (standard deviation) of age for women and men were 30.5 (6.8) and 34.5 (7.6) respectively. More than one third of women $(34.8 \%)$ have middle studies and more than one third of men $(35.0 \%)$ had high school diploma. Most of the couples (69.2\%) reported that their monthly income was sufficient for life expenses. The occupation of about one third of the participated men (36.7\%) was self-employed, and majority of women (83.6\%) were housewife. About $44.7 \%$ of women and $42.8 \%$ of men has normal BMI (Table 2 ).

Mean (standard deviation) of the perceived stress grade among women was 27.4 (6.0) and it was 25.9 (5.3) for men out of 0-56 and there was statistically significant difference among men and women regarding perceived stress $(\mathrm{P}<0.001)$. The results of bivariate tests showed that there was statistically significant difference in women among total grade of perceived stress and sufficiency variable of monthly income with life expenses, type of current received treatment, reason of action for treatment, and contraceptive method $(\mathrm{P}<0.05)$ and also there was statistically significant difference in men among the grade of perceived stress and sufficiency variable of monthly 
Table 1. Socio-demographic characteristics $(n=644)$

\begin{tabular}{|c|c|c|c|}
\hline Variable & $N(\%)$ & Variable & $N(\%)$ \\
\hline Infertility duration (year) & & Duration of marriage (year) & \\
\hline$<5$ & $233(36.2)$ & $<5$ & $190(29.5)$ \\
\hline 3-5 & $151(23.4)$ & $3-5$ & $147(22.8)$ \\
\hline$>5$ & $260(40.4)$ & $>5$ & $307(47.7)$ \\
\hline Use of contraception & & Treatment duration (year) & \\
\hline Yes & $441(68.5)$ & $<5$ & $341(53.0)$ \\
\hline No & $203(31.5)$ & $3-5$ & $133(20.7)$ \\
\hline Term use of contraceptive methods (month) & & $>5$ & $170(26.3)$ \\
\hline$<3$ & $111(56.1)$ & Contraceptive method used & \\
\hline 3 or over & $87(43.9)$ & Tablet & $76(36.2)$ \\
\hline History of previous treatment failure & & Condom & $40(19.0)$ \\
\hline Yes & $230(35.5)$ & Natural & $80(38.1)$ \\
\hline No & $411(64.1)$ & IUD & $12(6.7)$ \\
\hline Received Infertility treatment & & Number of treatment failure & \\
\hline Semen Insemination (IUI) & $241(40.4)$ & $<2$ & $247(61.3)$ \\
\hline Stimulate ovulation\& (IUI) & $91(15.3)$ & $2-4$ & $93(23.1)$ \\
\hline In vitro fertilization(IVF) & $202(33.9)$ & $>4$ & $63(15.6)$ \\
\hline Other methods* & $62(10.4)$ & Congestion Index** & \\
\hline Cause of infertility & & Low population & $590(92.2)$ \\
\hline Female factor & $290(32.9)$ & The average population & $39(6.1)$ \\
\hline Male factor & $192(30.2)$ & Populous & $11(1.7)$ \\
\hline Reasons not given & $116(18.3)$ & & \\
\hline Causes of male and female & $118(18.6)$ & & \\
\hline
\end{tabular}

${ }^{*}$ Include medicine, surgery, microinjection and embryo donation. ${ }^{* *}$ Congestion index by dividing the number of family rooms, excluding bathrooms and toilets were obtained, and the low-level populations(less than two persons per room), the average population (two to three persons per room) and large (more than three people per room), respectively.

Table 2. Socio-demographic characteristics $(n=644)$

\begin{tabular}{|c|c|c|c|c|c|}
\hline \multirow[b]{2}{*}{ Variable } & \multirow{2}{*}{$\begin{array}{c}\text { Women } \\
\mathrm{N}(\%)\end{array}$} & \multicolumn{2}{|l|}{ Men } & $\begin{array}{c}\text { Women } \\
\mathrm{N}(\%)\end{array}$ & \multirow{2}{*}{$\begin{array}{l}\text { Men } \\
\mathrm{N}(\%)\end{array}$} \\
\hline & & $\mathrm{N}(\%)$ & Variable & N (\%) & \\
\hline Education & & & Age(year) & & \\
\hline Secondary school & $112(34.8)$ & $105(32.8)$ & $<30$ & $150(46.6)$ & $72(22.3)$ \\
\hline High school & $26(8.1)$ & $25(7.8)$ & $30-40$ & $152(47.2)$ & $195(60.6)$ \\
\hline Diploma & $101(31.4)$ & $112(35.0)$ & $>40$ & $20(6.2)$ & $55(17.1)$ \\
\hline University & $83(25.7)$ & $78(24.4)$ & Mean (SD) & $30.5(6.8)$ & $34.5(7.6)$ \\
\hline \multicolumn{2}{|c|}{ Sufficiency of income for living expenses } & & Family members & & \\
\hline Absolutely & $66(20.5)$ & $61(19.0)$ & My family & $8(2.5)$ & $31(9.6)$ \\
\hline To some extent & $218(67.7)$ & $277(70.7)$ & My spouse family & $31(9.6)$ & $8(2.5)$ \\
\hline Completely & $38(11.8)$ & $33(10.3)$ & Me \& spouse & $282(87.9)$ & $282(87.9)$ \\
\hline \multicolumn{2}{|c|}{ Body mass index (BMI) $(\mathrm{kg} / \mathrm{m} 2) *$} & & Causes of infertility treatment & & \\
\hline Low weight & $6(1.9)$ & $3(0.9)$ & Personal desire & $281(87.3)$ & $276(86.8)$ \\
\hline Normal & $143(44.7)$ & $137(42.8)$ & Pressure of spouse & $25(7.8)$ & $18(5.7)$ \\
\hline Overweight & $130(40.6)$ & $141(44.1)$ & Pressure of family \& friends & $16(5.0)$ & $24(7.5)$ \\
\hline \multirow[t]{7}{*}{ Obese } & $41(12.8)$ & $39(12.2)$ & Occupation & & \\
\hline & & & Worker & - & 89 (27.6) \\
\hline & & & Shopkeeper & - & 35 (10.9) \\
\hline & & & Employee & - & $80(24.8)$ \\
\hline & & & Self-employed & - & $118(36.7)$ \\
\hline & & & Housekeeper & $266(83.6)$ & - \\
\hline & & & Employee & $52(16.4)$ & - \\
\hline
\end{tabular}

*Body Mass Index (BMI) $\left(\mathrm{kg} / \mathrm{m}^{2}\right)$ by the World Health Organizationin to 4 groups have been devided: Low weight (less than 18.5), normal (18.5 to 24.99$)$, overweight ( 25 to 29.99 ) and obese (30 and older) divisions. 
income with life expenses, occupation status and infertility reason $(\mathrm{P}<0.05)$.

According to multivariate linear regression test, the variables of monthly income sufficiency for life expenses, method of treatment, reason for treatment, contraceptive methods were the predictors of perceived stress among women and totally could predict $38 \%$ of the perceived stress variance among women. Meanwhile, the variables of monthly income sufficiency for life expenses, occupational status and etiology of infertility were the predictors of perceived stress among men and predicted $14 \%$ of the perceived stress among men (Table 3 ).

\section{Discussion}

According to the results obtained from this study, the mean of perceived stress among women was higher than men. The variables of monthly income sufficiency for life expenses, method of current treatment, reason of taking action for treatment, contraceptive methods were the predictors of perceived stress among women and the variables of monthly income sufficiency for life expenses, occupational status, and etiology of infertility were the predictors of perceived stress for men.
In this study, the grade of perceived stress in women was higher than men which show higher stress among women compared to men. The results of study in Hungary, which was done on the effect of gender on infertility stress showed that stress resulted from infertility, social concerns related to infertility and public health problems among the infertile women are more than infertile men which is consistent to the findings of our study (9). Such findings have been reported in several other studies $(10,11,22)$. In a study by Alizadeh et al. on 30 infertile women and 30 men, it was reported that although infertility stress was not significant among women and men, the grades of infertile women in all the components of infertility stress was more than infertile men (23).

One of the predictors of perceived stress was the sufficiency of monthly income for life expenses such that perceived stress for the couples who fully reported the sufficiency of monthly income for life expenses was lower than those who expressed it a little or did not express it at all. In a study by Fotokian et al. in Ramsar, the most correlation was seen between stressful events of life with economic status such that the grades of stressful events of life were higher among who knew their income as weak (24). Many

Table 3. Socio-demographic Predicators of Perceived Stress $(n=644)$

\begin{tabular}{|c|c|c|c|c|}
\hline \multirow{2}{*}{ Variable } & \multicolumn{2}{|l|}{ Men } & \multicolumn{2}{|c|}{ Women } \\
\hline & (Cl 95\%) $\beta$ & $\mathbf{P}$ & (Cl 95\%) $\beta$ & $\mathbf{P}$ \\
\hline \multicolumn{5}{|l|}{ Cause of treatment } \\
\hline Personal desire (reference) & - & - & 0 & 0 \\
\hline Spouse pressure & - & - & 0.18 (0.11 to 9.11$)$ & 0.045 \\
\hline Family pressure & - & - & $-0.14(-9.70$ to 9.98$)$ & 0.078 \\
\hline \multicolumn{5}{|l|}{ Cause of infertility } \\
\hline Female factor & 0 & 0 & - & - \\
\hline Male factor & $0.08(-0.45$ to 2.35$)$ & 0.184 & - & - \\
\hline Reasons not given & $-0.03(-2.07$ to 1.23$)$ & 0.619 & - & - \\
\hline Causes of male $\&$ female & 0.09 (-0.40 to 2.86$)$ & 0.139 & - & - \\
\hline \multicolumn{5}{|l|}{ Received Infertility treatment } \\
\hline Semen Insemination (IUI) & - & - & 0 & 0 \\
\hline Stimulate ovulation \& (IUI) & - & - & 0.19 (0.16 to 6.84$)$ & 0.040 \\
\hline In vitro fertilization (IVF) & - & - & 0.24 (0.78 to 6.43 ) & 0.013 \\
\hline Other methods* & - & - & 0.34 (3.36 to 10.94$)$ & $<0.001$ \\
\hline \multicolumn{5}{|c|}{ Sufficiency of income for living expenses } \\
\hline Absolutely & 0 & 0 & 0 & 0 \\
\hline To some extent & $-0.12(-2.94$ to 0.08$)$ & 0.064 & 0.27 (1.02 to 7.06$)$ & 0.009 \\
\hline Completely & $-0.02(-2.79$ to 1.78$)$ & 0.662 & 0.21 (0.06 to 9.98$)$ & 0.047 \\
\hline \multicolumn{5}{|l|}{ Occupation } \\
\hline Worker & 0 & 0 & - & - \\
\hline Shopkeeper & $-0.009(-1.54$ to 1.32$)$ & 0.878 & - & - \\
\hline Employee & $0.08(-0.48$ to 3.36$)$ & 0.143 & - & - \\
\hline Self-employed & $-0.03(-1.97$ to 1.04$)$ & 0.548 & - & - \\
\hline \multicolumn{5}{|l|}{ Contraceptive method use ${ }^{* *}$} \\
\hline Reliable (reference) & - & - & 0 & 0 \\
\hline Unreliable & - & - & $-0.19(-5.08$ to -0.17$)$ & 0.036 \\
\hline Adjusted $R^{2}$ & \multicolumn{2}{|l|}{0.14} & \multicolumn{2}{|l|}{0.38} \\
\hline
\end{tabular}


researches indicate the highness of stress level among those who do not have sufficient income for supplying their expenses (25-28).

One of the other predictors of perceived stress was the method of received treatment such that perceived stress among women who received two treatments of Intrauterine insemination and ovulation simultaneously was higher than the perceived stress among those who have done other treatment methods like Intra-uterine insemination or IVF and probably the highness of multiple treatment expenses or being worried of the failure of a more effective method can justify this higher stress among people. In a study by Gradvohl et al. in 2013 on infertile couples, higher level of stress was obtained among those who followed infertility treatment and such stress was different among men and women and different mental support was proposed for men and women in it (22). Meanwhile, in a study which was done on the couples who were treated for infertility, high stress was shown on these people which stress was reduced by an efficient and economical method (26).

The reason of taking action for infertility treatment in this study as one of the predictors of perceived stress among women was obtained such than those women who mentioned their husband's pressure for taking action to treatment, had the highest level of stress compared to those who expressed the reason in their personal desire or pressure of others and probably the reason of such high stress is that the thoughts and talk of husband had the most effect on person's life and mostly people try to keep their family's society. The study by Chang and $\mathrm{Mu}$ on the couples who received infertility treatment showed that the couples who have family-centered view, mentioned experiences of stress resulted from their family's pressure about infertility (29). In this study, record of using contraception method was one of the other predictors of perceived stress among women such that those who mentioned the record of using confident contraception, had higher perceived stress grade compared to those who expressed the conception of uncertain contraception which probably due to incorrect assumptions in the society and following it due to incorrect thoughts of these people about confident contraceptives such as pills, ampoules, IUD which can cause infertility.

In the results of this study, the etiology of infertility was one of the other predictors of perceived stress among men such that in men whose were expressed as the etiology of infertility, had higher perceived stress, the simultaneous availability of men and women etiologies was in lower rank due to perceived stress grade. The study by Sifer et al on the couples who were referred for IVF treatment, described the infertility stress higher in women compared to men while in men's infertility problem, stress is higher in women and men compared to when the etiology is women's problem and such findings is consistent with our study (30) which probably the reason of higher stress in infertility due to men's reasons is the available cultural issues in the society and men's infertility is assumed as an strange and far-fetched factor and for most of the people, the occurrence of such problem is not acceptable in men. In the current study, the occupational status of men was one of the other predictors of perceived stress such that the lowest grade of perceived stress was obtained among employees and the highest grade was obtained among workers which is assumed that economically workers are under pressure in supplying the higher expenses of infertility treatment compared to employees who have a fixed income for treatment expenses so the workers tolerate higher stress. One of the limitations of this study was due to its sectional nature and the relationships between perceived stress and social-individual particulars are not necessarily indicating the casual relationship. The other limitation was due to easy and available sampling in this study which reduces the generalization of results.

\section{Conclusion}

In whole, the findings of this research indicate that perceived stress among infertile women is higher than infertile men and regarding the availability of vicious cycle between infertility and stress which causes many problems for being succeeded in treatment, it seems necessary to execute supporting and consulting problems focusing on the predictors of perceived stress among infertile couples for reducing stress in these people especially women aimed at promoting the health.

\section{Ethical issues}

The local ethics committee approved the study.

\section{Conflict of interests}

Authors declare that there is no any conflict of interests.

\section{Acknowledgments}

This study was approved and was sponsored by the Research Department of Tabriz University of Medical Sciences (Code Number: 9242). The authors would like to thanks Tabriz University of Medical Sciences, Al Zahra Hospital President and all those who helped us in this study and also respectable couple finally had to announce partnership.

\section{References}

1. Newton CR, Sherrard W, Glavac I. The fertility problem inventory: measuring perceived infertilityrelated stress. Fertil Steril 1999;72(1):54-62.

2. Gibson DM, Myers JE. The effect of social coping resources and growth-fostering relationships on infertility stress in women. Journal of Mental Health Counseling 2002;24(1):68-80.

3. Berek JS. Berek \& Novak's gynecology. 15th ed. Philadelphia: Lippinicott Williams and Wilkins; 2012.

4. Moura-Ramos M, Gameiro S, Canavarro MC, Soares I. Assessing infertility stress: re-examining the factor structure of the fertility problem inventory. Hum Reprod 2011;27(2):496-505.

5. Roupa Z, Polikandrioti M, Sotiropoulou P, Faros E, 
Koulouri A, Wozniak G, et al. Causes of infertility in women at reproductive age. Isr J Health Policy Res 2009;3(2):80-7.

6. Pinar G, Zeyneloglu HB. Quality of life, anxiety and depression in turkish women prior to receiving assisted reproductive techniques. Int J Fertil Steril 2012; 6(1):1-12.

7. Mohammad K, Ardalan A. An overview of the epidemiology of primary infertility in Iran. J Reprod Infertil 2009;10(3):213-6.

8. Kumar D. Prevalence of female infertility and its socioeconomic factors in tribal communities of central India. Rural Remote Health 2007;7(2):1-5.

9. Cserepes RE, Kollar J, Sapy T, Wischmann T, Bugan A. Effects of gender roles, child wish motives, subjective well-being, and marital adjustment on infertilityrelated stress: a preliminary study with a Hungarian sample of involuntary childless men and women. Arch Gynecol Obstet 2013; 288(4):925-32.

10. Peterson BD, Newton CR, Feingold T. Anxiety and sexual stress in men and women undergoing infertility treatment. Fertil Steril 2007; 88(4):911-4.

11. Donarelli Z, Lo Coco G, Gullo S, Marino A, Volpes A, Allegra A. Are attachment dimensions associated with infertility-related stress in couples undergoing their first IVF treatment? A study on the individual and cross-partner effect. Hum Reprod 2012; 27(11):3215-25.

12. Khodakarami N, Hashemi S, Seddigh S, Hamdiyeh M, Taheripanah R. Life experience with infertility; a phenomenological study. J Reprod Infertil 2010;10(4):287-297.

13. Sheiner E, Sheiner EK, Potashnik G, Carel R, ShohamVardi I. The relationship between occupational psychological stress and female fertility. Occup Med 2003;53(4):265-9.

14. Stark MA, Brinkley RL. The relationship between perceived stress and health-promoting behaviors in high-risk pregnancy. J Perinat Neonatal Nurs 2007;21(4):307-14.

15. Rashidi B, Hosseini S, Beigi P, Ghazizadeh M, Farahani MN. Infertility stress: the role of coping strategies, personality trait, and social support. J Fam Plann Reprod Health Care 2011;5(4):103-10.

16. Andrews FM, Abbey A, Halman LJ. Is fertility-problem stress different? the dynamics of stress in fertile and infertile couples. Fertil Steril 1992;57(6):1247-53.

17. Peterson BD, Pirritano M, Christensen U, Schmidt L. The impact of partner coping in couples experiencing infertility. Hum Reprod 2008;23(5):1128-37.

18. Benazon N, Wright J, Sabourin S. Stress, sexual satisfaction, and marital adjustment in infertile couples. J Sex Marital Ther 1992;18(4):273-84.

19. Sepahvand T, Gilani B, Zamani R. Relationship between attributional styles with stressful life events and general health. Psychol Res 2007;9(3,4):33-46.

20. Beasley M, Thompson T, Davidson J. Resilience in response to life stress: the effects of coping style and cognitive hardiness. Hum Reprod 2003;34(1):77-95.

21. Nohi E, Abdolkarimi M, Rezaeian M. Quality o f life and its relashionship with stress and coping strategies in coronary heart disease patients. J Rafsanjan Univ Med Sci 2011;2(10):127-37.

22. Gradvohl SM, Osis MJ, Makuch MY. [Stress of men and women seeking treatment for infertility]. Rev Bras Ginecol Obstet 2013; 35(6):255-61.

23. Alizadeh T, Farahani M, Shahraray M, Alizadegan S. The relationship between self esteem and locus of control with infertility related stress of no related infertile men and women. J Reprod Infertil 2005;6(2):194-205.

24. Fotokian Z, Ghaffari F, Keyhanian Sh. The relation of stressful life events and cancer in refers to oncology unit in Ramsar imam Saggad hospital. Sci J Hamadan Nurs Midwifery Fac 2008;16(1):11-21.

25. Ell K, Xie B, Wells A, Nedjat-Haiem F, Lee PJ, Vourlekis B. Economic stress among low-income women with cancer: effects on quality of life. Cancer 2008; 112(3):616-25.

26. Matthiesen S, Klonoff-Cohen $\mathrm{H}$, Zachariae $\mathrm{R}$, Jensen-Johansen MB, Nielsen BK, Frederiksen Y, et al. The effect of an expressive writing intervention (EWI) on stress in infertile couples undergoing assisted reproductive technology (ART) treatment: a randomized controlled pilot study. $\mathrm{Br} \mathrm{J}$ Health Psychol 2012; 17(2):362-78.

27. Norbeck JS, Anderson NJ. Life stress, social support, and anxiety in mid- and late-pregnancy among low income women. Res Nurs Health 1989; 12(5):281-7.

28. Zachariah R. Social support, life stress, and anxiety as predictors of pregnancy complications in low-income women. Res Nurs Health 2009; 32(4):391-404.

29. Chang SN, Mu PF. Infertile couples' experience of family stress while women are hospitalized for ovarian hyperstimulation syndrome during infertility treatment. J Clin Nurs 2008; 17(4):531-8.

30. Sifer C, Handelsman O, Grange E, Porcher R, Poncelet C, Martin-Pont B, et al. An auto-controlled Prospective comparison of two embryos culture media (G III series versus (ISM) for IVF and ICSI treatment. J Assist Reprod Genet 2009;26:575-81.

Copyright ( 92014 The Author(s); This is an open-access article distributed under the terms of the Creative Commons Attribution License (http://creativecommons.org/licenses/by/4.0), which permits unrestricted use, distribution, and reproduction in any medium, provided the original work is properly cited. 